\title{
Extensive Genetic Variation at the Sr22 Wheat Stem Rust Resistance Gene Locus in the Grasses Revealed Through Evolutionary Genomics and Functional Analyses
}

\author{
M. Asyraf Md. Hatta, ${ }^{1,2}$ Sreya Ghosh, ${ }^{1}$ Naveenkumar Athiyannan, ${ }^{3,4}$ Terese Richardson, ${ }^{3}$ \\ Burkhard Steuernagel, ${ }^{1}$ Guotai Yu, ${ }^{1}$ Matthew N. Rouse, ${ }^{5,6}$ Michael Ayliffe, ${ }^{3}$ Evans S. Lagudah, ${ }^{3}$ \\ Guru V. Radhakrishnan, ${ }^{1,+}$ Sambasivam K. Periyannan, ${ }^{3,4,+}$ and Brande B. H. Wulff ${ }^{1,+}$ \\ ${ }^{1}$ John Innes Centre, Norwich Research Park, Norwich, NR4 7UH, United Kingdom \\ ${ }^{2}$ Department of Agriculture Technology, Faculty of Agriculture, Universiti Putra Malaysia, Serdang, Malaysia \\ ${ }^{3}$ Commonwealth Scientific and Industrial Research Organization (CSIRO), Agriculture and Food, General Post Office Box \\ 1700, Canberra, ACT 2601, Australia \\ ${ }^{4}$ Centre for Crop Science, Queensland Alliance for Agriculture and Food Innovation, University of Queensland, Brisbane, \\ Australia \\ ${ }^{5}$ United States Department of Agriculture-Agricultural Research Service Cereal Disease Laboratory, St. Paul, MN 55108, \\ U.S.A. \\ ${ }^{6}$ Department of Plant Pathology, University of Minnesota, St. Paul, MN 55108, U.S.A.
}

Accepted 7 August 2020.

In the last 20 years, severe wheat stem rust outbreaks have been recorded in Africa, Europe, and Central Asia. This previously well controlled disease, caused by the fungus Puccinia graminis f. sp. tritici, has reemerged as a major threat to wheat cultivation. The stem rust $(S r)$ resistance gene $S r 22$ encodes a nucleotide-binding and leucine-rich repeat receptor which confers resistance to the highly virulent African stem rust isolate Ug99. Here, we show that the $\mathrm{Sr} 22$ gene is conserved among grasses in the Triticeae and Poeae lineages. Triticeae species contain syntenic loci with single-copy orthologs of $\mathrm{Sr} 22$ on chromosome 7, except Hordeum vulgare, which has experienced major expansions and rearrangements at the locus. We also describe $14 \mathrm{Sr} 22$ sequence variants obtained from both Triticum boeoticum and the domesticated form of this species, T. monococcum, which have been postulated to encode both functional and nonfunctional $S r 22$ alleles. The nucleotide

${ }^{\dagger}$ Corresponding authors: B. B. H. Wulff; brande.wulff@jic.ac.uk;

S. K. Periyannan; sambasivam.periyannan@csiro.au; and

G. V. Radhakrishnan; guru.radhakrishnan@jic.ac.uk

Funding: Support was provided by the Two Blades Foundation (grant number BB/L011794/1); the United States Department of AgricultureAgricultural Research Service (USDA-ARS) National Plant Disease Recovery System; the Biotechnology and Biological Sciences Research Council (BB/P016855/1), U.K.; Durable Rust Resistance in Wheat (DRRW), Borlaug Global Rust Initiative, United States; and the Grains Research and Development Corporation, Australia. M. A. Md. Hatta was supported by a fellowship from Universiti Putra Malaysia (UPM), Malaysia. S. Ghosh was supported by a Monsanto Beachell Borlaug International Fellowship. G. V. Radhakrishnan was supported by a BBSRC Discovery Fellowship (grant number BB/S011005/1). N. Athiyannan was supported by an Australian Government Research Training Program Scholarship.

*The $\boldsymbol{e}$-Xtra logo stands for "electronic extra" and indicates that supplementary materials are published online.

The author(s) declare no conflict of interest.

(c) (1) () C Copyright ( $\odot 2020$ The Author(s). This is an open access article (c) (1) (3) () distributed under the CC BY-NC-ND 4.0 International license. sequence analysis of these alleles identified historical sequence exchange resulting from recombination or gene conversion, including breakpoints within codons, which expanded the coding potential at these positions by introduction of nonsynonymous substitutions. Three $\mathrm{Sr} 22$ alleles were transformed into wheat cultivar Fielder and two postulated resistant alleles from Schomburgk (hexaploid wheat introgressed with $T$. boeoticum segment carrying $S r 22$ ) and $T$. monococcum accession PI190945, respectively, conferred resistance to $P$. graminis $\mathbf{f}$. $s p$. tritici race TTKSK, thereby unequivocally confirming $\mathrm{Sr} 22$ effectiveness against Ug99. The third allele from accession PI573523, previously believed to confer susceptibility, was confirmed as nonfunctional against Australian P. graminis f. sp. tritici race 98-1,2,3,5,6.

Keywords: plant biotechnology, resistance gene, Sr22, stem rust, Ug99, wheat

Stem rust, caused by Puccinia graminis f. sp. tritici, is one of the most devastating fungal diseases of wheat. Historically, this disease has caused dramatic, widespread crop failures leading to significant yield losses worldwide (Singh et al. 2015). The deployment of resistant cultivars and, in some locations, the eradication of the alternate host, common barberry (Berberis vulgaris), has kept the disease under control over the past several decades (Peterson 2001). However, in Uganda in the 1998-99 growing season, the $P$. graminis f. sp. tritici race TTKSK (Ug99) emerged, which was virulent on the majority of the world's wheat cultivars, including those carrying the previously highly effective stem rust $(S r)$ resistance gene $S r 31$, thereby raising major concerns for global food security (Pretorius et al. 2000). Subsequently, Ug99 and variants thereof have spread throughout eastern and southern Africa, Yemen, and Iran (Nazari et al. 2009; Patpour et al. 2016; Pretorius et al. 2010; Singh et al. 2015). Moreover, this race has evolved rapidly and 13 TTKSK variants have been identified with virulence on $\mathrm{Sr} 24$, Sr36, and SrTmp (Fetch et al. 2016; Patpour et al. 2016; Pretorius et al. 2012; 
Singh et al. 2015; Terefe et al. 2018). In more recent years, additional stem rust outbreaks have been reported in Europe (Berlin 2017; Bhattacharya 2017; Olivera Firpo et al. 2017), Asia (Shamanin et al. 2016), and Africa (Olivera et al. 2015) caused by other highly virulent $P$. graminis f. sp. tritici races unrelated to the Ug99 lineage. Collectively, Ug99 and these newer $P$. graminis f. sp. tritici races pose a significant threat to global food security.

Fungicide application only partially controls wheat stem rust disease. The deployment of resistance $(R)$ genes is the most economical and environmentally sustainable control method. In all, $60 \mathrm{Sr}$ resistance genes have been designated to date (Chen et al. 2018a; McIntosh et al. 2017; Zhang et al. 2020) and 11 major, dominant $\mathrm{Sr}$ genes have been cloned (Arora et al. 2019; Chen et al. 2018b, 2020; Mago et al. 2015; Periyannan et al. 2013; Saintenac et al. 2013; Steuernagel et al. 2016; Zhang et al. 2017; Zhang et al. 2020). These cloned $S r$ genes encode intracellular immune receptor proteins containing nucleotide-binding and leucine-rich repeat domain (NLR) proteins (in the case of $S r 13, S r 21, S r 22$, Sr26, Sr33, Sr35, Sr45, Sr46, Sr50, and Sr61) or a tandem kinase (Sr60). In contrast only two $P$. graminis $\mathrm{f}$. sp. tritici avirulence (Avr) genes have been cloned that each encode a corresponding pathogen effector molecule recognized by the $\mathrm{Sr} 35$ and $\mathrm{Sr} 50$ NLR proteins, respectively (Chen et al. 2017; Salcedo et al. 2017).

Recent genetic and genomic studies have provided insights into the molecular evolution of NLR genes and the molecular mechanisms that generate sequence diversity in these genes. Genome sequencing has shown that most NLRs exist as members of small clusters of sequence-related paralogs, such as the lettuce Dm3/13 (Meyers et al. 1998b) and tomato I2 clusters (Ori et al. 1997). In potato, $73 \%$ of mapped NLR genes are grouped into 63 clusters in the genome (Jupe et al. 2012), with similar NLR clusters observed in the Arabidopsis and rice genomes (Bai et al. 2002; Meyers et al. 1999). These gene clusters are thought to provide a reservoir of genetic variation to generate new resistance specificities by recombination or gene conversion (Ellis et al. 2000; Hulbert et al. 2001; Michelmore and Meyers 1998). Extensive historical recombination between paralogs within $R$ gene clusters have been observed in tomato (Parniske et al. 1997), Arabidopsis (Meyers et al. 1998a), and flax (Dodds et al. 2001; Ellis et al. 1999) based on mosaic patterns of conserved sequence segments. Genetic analyses revealed that recombination played a central role in the evolution of new specificities at the $M, N$, and $P$ loci in flax (Dodds et al. 2001); the $R p 1$ rust resistance complex in maize (Hulbert 1997); and the $C f-4 / C f-9$ Milky Way locus in tomato (Parniske and Jones 1999; Parniske et al. 1997). In some cases, NLR genes exist as simple loci containing a single gene such as the Arabidopsis RPMI (Stahl et al. 1999) and RPP13 loci (Bittner-Eddy et al. 2000) and the flax $L$ locus (Ellis et al. 1999).

Unequal recombination at $R$ gene clusters has been observed relatively frequently at the maize $R p l$ locus (Sun et al. 2001) and, more rarely, at the lettuce Dm3 locus (Michelmore and Meyers 1998). Tandem duplication of paralogous genes by unequal crossover has been an important mechanism in generating sequence variation at Arabidopsis NLR loci (Meyers et al. 2003). Gene duplication can also explain copy number variation existing between haplotypes such as that observed at the lettuce Dm3 cluster (Kuang et al. 2004) and potato $M L B$ cluster (Jupe et al. 2012). At loci containing a single NLR, diversifying selection coupled with recombination between allelic variants can also result in the evolution of new alleles. This was observed in the flax $L$ locus, in which frequent interallelic recombination events produced at least a dozen novel alleles (Dodds et al. 2006). Very rarely, ectopic recombination between different clusters, even between those located on different chromosomes, may also occur (Parniske and Jones 1999). Consequently, although $R$ gene clusters usually contain closely related sequences, individual genes may be more related to sequences from other clusters within the genome than to members of the same cluster.

The $S r 22$ gene was recently cloned using a mutagenesis and sequence capture approach from a hexaploid wheat introgression line, Schomburgk, in which the gene had been introgressed into chromosome 7A from the diploid A genome relative, Triticum boeoticum (Steuernagel et al. 2016). This gene confers broad-spectrum resistance to multiple races of $P$. graminis f. sp. tritici, including the Ug99 race group (Steuernagel et al. 2016). Previously (Steuernagel et al. 2016), we identified 14 Sr22 sequence variants in T. boeoticum and T. monococcum, some of which were believed to confer functional Sr22 resistance (Rouse and Jin 2011a). Herein, we describe several more $S r 22$ alleles, provide evidence of historical sequence exchange in some alleles, and demonstrate that two of these alleles also confer functional $S r 22$ resistance. We also inspected grass genomes and transcriptomes and found that Sr22 likely arose in the last common ancestor of the Triticeae and Poeae lineages, and then evolved as a single gene locus, except in barley and oat, where the locus experienced pronounced independent expansions.

\section{RESULTS}

\section{The majority of Triticeae genomes contain single-copy} orthologs of $\mathrm{Sr} 22$ on chromosome 7 .

To understand the evolutionary history of $\mathrm{Sr} 22$, we conducted a comprehensive search for $S r 22$ homologs in 40 genomes and 122 transcriptomes covering a total of 80 plant species, 76 of which belong to the monocot lineage (Fig. 1A; Supplementary File S1). Phylogenetic analysis recovered Sr22 orthologs specifically in the genomes and transcriptomes of the Triticeae and Poeae species examined (Fig. 1B; Supplementary File $\mathrm{S} 2$ ). The $S r 22$ protein tree largely mirrored the phylogeny of the species studied here. In the Triticeae species, all but Hordeum vulgare possessed single-copy orthologs of Sr22. Microsynteny analysis of the Triticeae genomes revealed the presence of single-copy orthologs of $S r 22$ on chromosome 7 in each of the subgenomes of T. aestivum (7A, 7B, and 7D), T. turgidum (7A and 7B), and T. diccocoides (7A and 7B) wheat, as well as in the genomes of the wheat wild relative species Aegilops tauschii (on chromosome 7D) and T. urartu (not assigned to a chromosome because the available assembly is not chromosome level) (Fig. 2; Supplementary Fig. S1; Supplementary File S3). In the case of $H$. vulgare, we identified an $\mathrm{Sr} 22$ syntenic region on $7 \mathrm{H}$ containing multiple NLR loci (several of which were orthologous to $\mathrm{Sr} 22$ ) interspersed with other non-NLR genes, likely the result of local gene duplication and rearrangement events. To confirm that this was not due to assembly errors and to check whether this was a cultivar-effect specific to the $H$. vulgare 'Morex' or more broadly conserved in Hordeum spp., we conducted microsynteny analysis of other Hordeum accessions and found similar expansion of the Sr22 locus in H. vulgare 'Golden Promise' as well as H. vulgare var. nudum (Supplementary Fig. S2; Supplementary File S3). We also observed a similar expansion of the $\mathrm{Sr} 22$ locus in the genomes of the diploid oat progenitors Avena atlantica and A. eriantha from the Poeae lineage (Fig. 2; Supplementary File S3). On the other hand, although our searches uncovered other NLRs homologous to Sr22 in Brachypodium distachyon and the Oryza spp. studied here, orthologs of $S r 22$ were not found in these species (Supplementary File S2). Although Sr22 orthologs were not detected, regions exhibiting conservation of microsynteny to those in the Triticeae species investigated above could be identified in Oryza sativa and $B$. distachyon (Fig. 2). Of the 20 genes flanking the $S r 22$ ortholog in the 7D subgenome of T. aestivum, homologs of five and six of these 
A

B Aegilops tauschii TQ27

3egilops tauschi KU-2627

Aegilops tauschil KU-2003

Aegilops tauschil KU-208
Aegilops tauschii KU-2093

- Aegilops tauschii AT 8 /78 7D

Aegilops tauschii ATL

Aegilops tauschil KU-2124

$\checkmark$ Aegilops tauschil AL $8 / 78$

- Aegilops tauschii KU-2078

Aegilops tauschill Pl499262

- Aegilops speltoides B

- Triticum aestivum 7A durum $7 A$

- Triticum dicoccoides 7A

Aeqliops tauschii ERS399496

Triticum aestivum $7 D$

- Aegilops sharonensis 2189

Aegilops sharonensis 542237

Aegilops speltoides ERS399496

Aegilops sharonensis 396

gilops sharonensis 546

Arificum aestivum $7 \mathrm{~B}$

Flagellariaceae 1 (T)

Joinvilleaceae 1 (T)

Ecdeiocoleaceae 1 (T)

Anomochlooideae 1 (T)

Panicoideae 6 G

Chloridoideae 2 G

Oryzoideae 17 G (T)

Bambusoideae 1 (T)

Nardeae 1 (T)

Meliceae 1 (T)

Stipeae 2 (T)

Brachypodieae 1 G

Poeae $12 \mathrm{G}(\mathrm{T}$

Bromeae 1 (T)

Triticeae 11 G $\mathrm{T}$

() Genome

(T)Transcriptome

P Pangenome

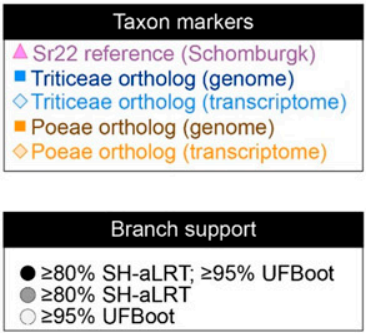

Tricum turgidum ssp. durum 7B

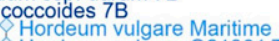
Hordeum vulgare 21861 Hordeum vulgare Q21861 T2 3 Hordeum vulgare $\mathrm{V}$ Hordeum vulgare WBDC109

Hordeum vulgare Commander Hordeum vulgare Commander ordeum vulgare Clino4196 T Hordeum vulgare Igri T2 Hordeum vulgare $7 \mathrm{H}$ Hordeum vulgare Hindmarsh Hordeum vulgare Cl16153 T Hordeum vulgare Cl16513 T2 Hordeum vulgare $\mathrm{Cl} 16147$ Hordeum vulgare WBDC259 Hordeum vulgare 7 ordeum vulgare WBDC 110 Hordeum vulgare WBDC013 T1 Hordeum vulgare WBDC013 T Hordeum vulgare WBDC013 T Hordeum vulgare WBDCO13 T5 Hordeum vulgare WBDC013 Hordeum vulgare BCD12 Horceum vugare Barke ordeum vugare Hordeum vulgare BCD47 T2
Hordeum vulgare WBDCO08 ordeum vulgare WBDC008 T2 Hordeum vulgare WBDC085

- Hordeum vulgare WBD

$\longrightarrow$ Hordeum vumgare SusPtrit

- Hordeum vulgare Duplex T1 8 Hordeum vulgare 15 T. Hordeum vulgare 15 T3 Hordeum vulgare 15 Triticeae ortholog (genome) Triticeae ortholog (transcriptome) Poeae ortholog (genome)

Poeae ortholog (transcriptome

Branch support

$\geq 80 \%$ SH-aLRT; $\geq 95 \%$ UFBoot $\geq 95 \%$ UFBoot

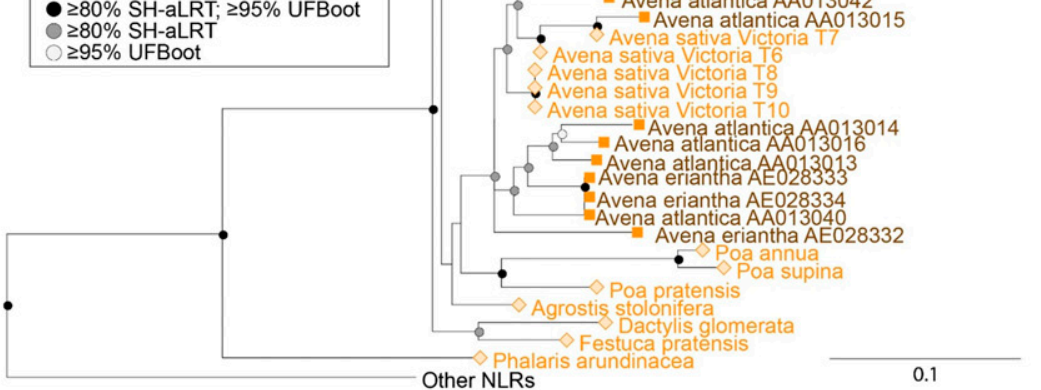

Fig. 1. Orthologs of $\operatorname{Sr} 22$ can be found in a wide range of species in the Triticeae and Poeae grass lineages. A, Phylogenetic representation of the plant and monocot lineages from which species were examined for the presence of $\mathrm{Sr} 22$ orthologs. Relationships between the lineages depicted are based on previous reports (Soreng et al. 2017; The Angiosperm Phylogeny Group et al. 2016) (Angiosperm Phylogeny Website). Numbers of species studied in each lineage and the type of dataset used are indicated in the figure. B, Maximum-likelihood phylogenetic tree of the $S r 22$ clade containing proteins from the Triticeae and Poeae lineages. The tree was constructed from an alignment corresponding to the NB-ARC1-ARC2 region of $S r 22$ using 38 known nucleotide-binding and leucinerich repeat domain (NLR) proteins as an outgroup. The query sequence used to retrieve these orthologous proteins was the Triticum aestivum Schomburgk Sr22 protein (highlighted in pink). Orthologs retrieved from genomes are shown in darker shades with square taxon markers while those retrieved from transcriptomes are shown in lighter shades with diamond markers. Triticeae $S r 22$ proteins are shown in blue while Poeae $S r 22$ proteins are shown in orange. Where more than one sequence was retrieved from a transcriptome without isoform information, the sequences are sequentially numbered starting from T1. Branch support values from 1,000 bootstrap replicates are indicated on the tree, which was constructed using the JTT+I+G4 evolutionary model. 
genes were found in contiguous regions on chromosomes 1 and 6 of B. distachyon and O. sativa, respectively (Fig. 2; Supplementary File S3). We further examined this through searches on the pangenomes of Brachypodium spp. and rice covering 54 and 3,010 accessions (Supplementary File S1) respectively, but again did not find any $\mathrm{Sr} 22$ orthologs (Supplementary File S4). The above findings suggest that the ancestral $S r 22$ gene likely evolved in the last common ancestor of the Triticeae and Poeae lineages. However, the strength of this hypothesis is limited by the lack of genomic resources for key grass lineages such as the Bromeae, a sister lineage to the Triticeae. As high-quality genomes of further grass species from evolutionarily important nodes become available, more comprehensive analyses can be carried out to test this hypothesis.

\section{Historical recombination at the $\mathrm{Sr} 22$ locus.}

In total, 14 Sr22 variants were previously PCR amplified and sequenced from $T$. monococcum and T. boeoticum accessions postulated to carry $\mathrm{Sr} 22$ (Steuernagel et al. 2016). Two of these sequence variants were excluded from further analysis due to possible germplasm redundancy. Screening of another 25 accessions identified an additional eight sequence variants from these two species. Six of these eight sequences were identical to those previously observed, bringing the total number of unique
$\mathrm{Sr} 22$ alleles identified to 14 . A possible new allele of $\mathrm{Sr} 22$, SrTm5, which has been recently mapped and characterized from T. monococcum accession PI306540 (Chen et al. 2018a), was also included in the analysis.

Nucleotide sequence comparison of these 15 sequences identified 136 informative polymorphic sites (IPS) (i.e., shared by at least two alleles) in the 2,841-bp Sr22 open reading frame (ORF) (Fig. 3). Based on sequence similarity, eight of these genes could be assigned into three groups (i.e., group $1=$ IG44855, Schomburgk, and IG44857; group $2=$ PI289605, PI330550, and PI190945; and group $3=$ PI573523 and IG44878) while the remaining seven alleles had no strong sequence affiliation with other variants. Group 1 shared greater than $99 \%$ sequence identity with each other whereas greater sequence variation was observed in the other two groups (Fig. $3)$. Several blocks of sequences containing conserved IPS $(>3)$ that deviated from the consensus sequence were shared between at least two $S r 22$ variants (Fig. 3, gray and black boxes). PI289605, PI330550, PI190945, PI573523, and IG44878 share almost continuous sequence identity from position 2,400 to 2,572 but PI289605 and PI330550 are most closely related to Schomburgk from position 276 to 2,272. This obvious mosaic pattern is indicative of sequence exchange between $\mathrm{Sr} 22$ alleles resulting from recombination or gene conversion as observed
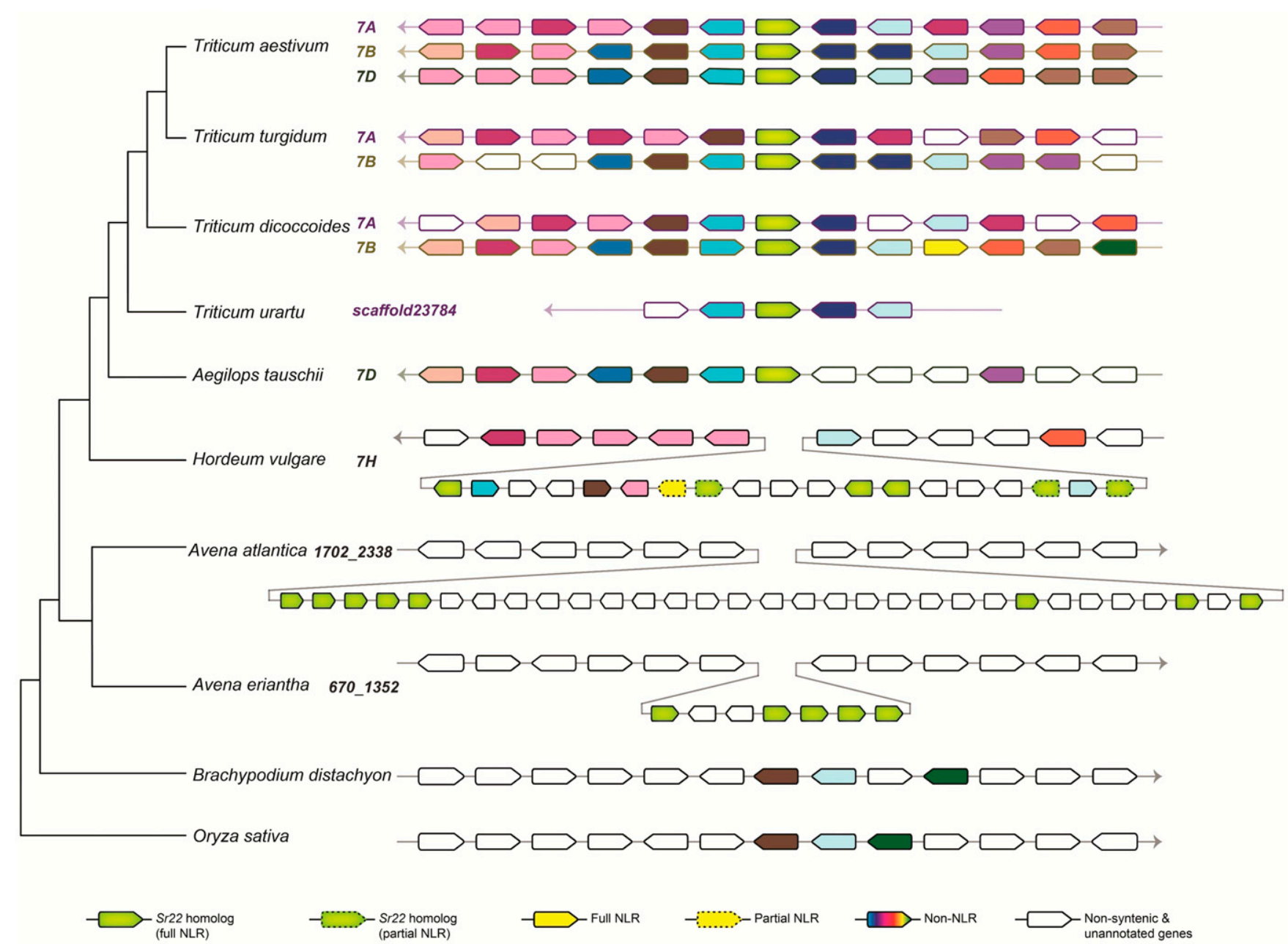

Fig. 2. $\operatorname{Sr} 22$ is a conserved nucleotide-binding and leucine-rich repeat domain (NLR) found on chromosome 7 in Triticeae species. Genomic regions of Triticeae species containing genes orthologous to $\mathrm{Sr} 22$ show microsynteny conservation. Sr22 orthologs were not detected in Oryza sativa and Brachypodium distachyon but regions exhibiting conservation of microsynteny to the region containing $\operatorname{Sr} 22$ in the Triticeae species investigated above could be identified. Genes are colored according to their predicted functional annotations. Sr 22 orthologs are colored green. Full-length NLR genes are shown with solid outlines while partial NLR genes are shown with dashed outlines (as predicted by NLR-Annotator). Gene families and model species' homologs are numerically coded for each gene. A question mark implies an unknown gene family or homolog. 
for the tomato Hcr9 genes (Parniske and Jones 1999; Parniske et al. 1997) and Arabidopsis RACl and RPP13 (Serra et al. 2018). A similar mosaic was seen for the PI190945 sequence which is most closely related to IG44857 from position 284 to 2,272 but then shares an IPS sequence signature with PI289605 and PI330550 from position 768 to 2,809 . Six potential intracodon recombination breakpoints were detected, all of which resulted in nonsynonymous codons (Fig. 3, red arrows).

\section{Confirmation of $\mathrm{Sr} 22$ variant function in stable wheat transgenics.}

Previously, a screen of 1,061 T. monococcum accessions for resistance to five $P$. graminis f. sp. tritici races with widely different virulence profiles (TTKSK [Ug99], TRTTF, TTTTF, QFCSC, and MCCFC) identified 55 accessions that were resistant to all five races. Of these, 15 accessions were postulated to carry functional alleles of $S r 22$ based on infection type similarities with known monogenic Sr22 lines (Rouse and Jin 2011b). Three $S r 22$ alleles, two of which were predicted to be functional, were transformed into wheat cultivar Fielder and tested for resistance function. This study focused on the coding sequence of the $\mathrm{Sr} 22$ genes. Therefore, to exclude phenotype differences potentially arising from differences between the regulatory sequences of these variants, a common synthetic promoter and terminator was used in each case.

A 9.7-kb sequence encoding the Schomburgk Sr22 sequence (Steuernagel et al. 2016) was fused to $5^{\prime}$ promoter and $3^{\prime}$ terminator sequences of the $S r 33$ gene (Periyannan et al. 2013) (Table 1). The Sr33 gene, although sequence unrelated to $S r 22$, is similar in that it also encodes a major, race-specific wheat stem rust NLR gene. Ten independent $T_{0}$ transgenic Fielder plants carrying this sequence (PC132) were all found to be resistant to the Australian wheat stem rust race $P$. graminis f. sp. tritici 98-1,2,3,5,6 (Table 2; Fig. 4). Moreover, the infection type was comparable with those seen on Fielder wheat transgenics containing an $\mathrm{Sr} 22$ transgene with endogenous regulatory sequences (construct PC103) (Steuernagel et al. 2016) (Tables 1 and 2; Fig. 4).

To facilitate more high-throughput allele testing, a Golden Gate-compatible construct (PC127) encoding Sr33 5' and 3' regulatory sequences and a "domesticated" $S r 22$ ORF were produced and introduced into Fielder wheat. Ten independent PC127 $\mathrm{T}_{0}$ families were tested with Australian P. graminis f. sp. tritici race 98-1,2,3,5,6 and found to be resistant, with an

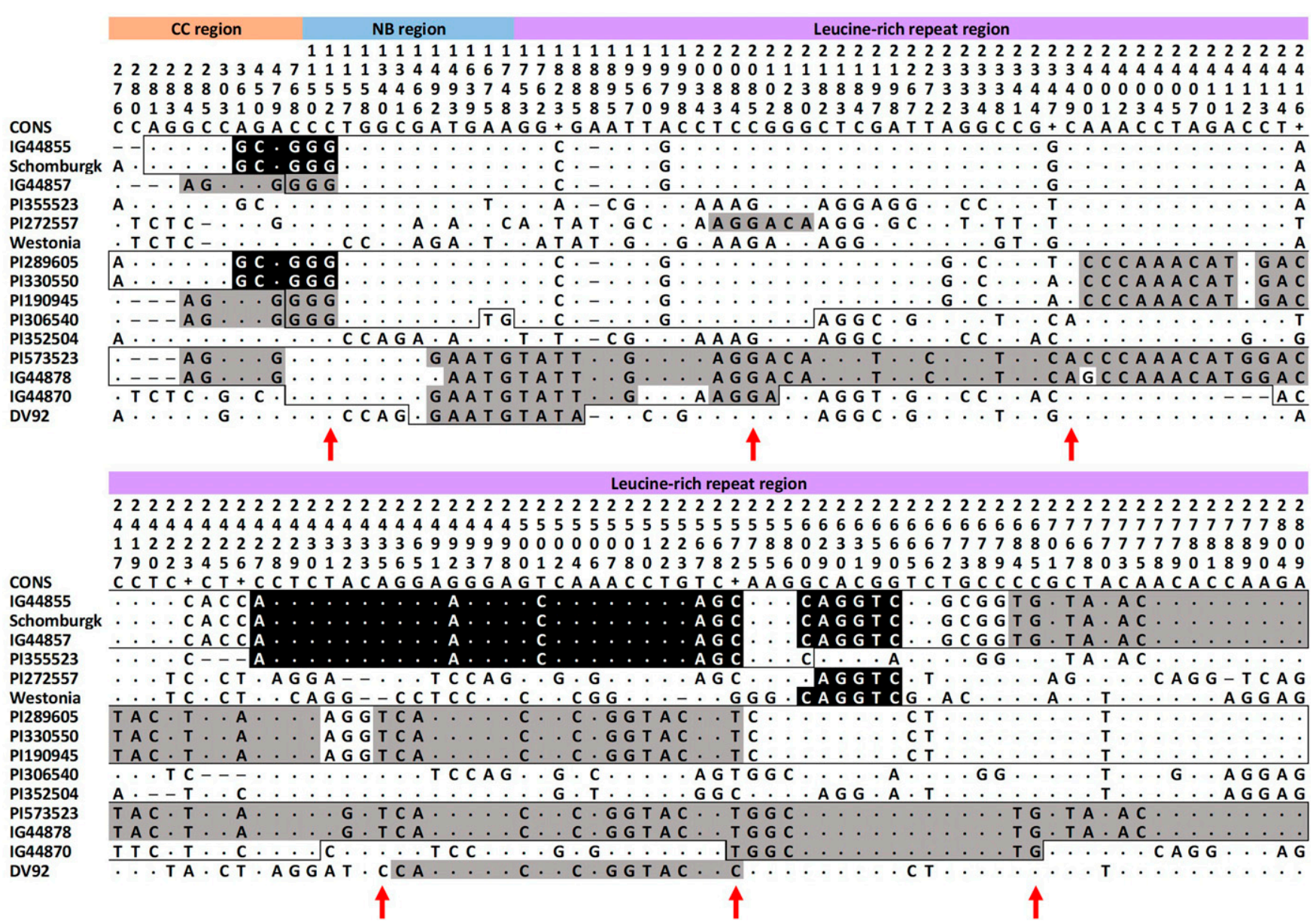

Fig. 3. Extensive historical intragenic recombination between $\operatorname{Sr} 22$ variants. Only informative polymorphic sites (IPS) (a polymorphic nucleotide which is shared between at least two sequences within the alignment) of the nucleotide sequences of the 15 Sr22 variants are shown. This reduces the total length of the sequence alignment from 2,841 nucleotides to 136 . Vertical numbers refer to nucleotide position within the global alignment of 2,841 nucleotides. The domain structure of the $S r 22$ protein according to Steuernagel et al. (2016) is indicated in the upper panel. Red arrows indicate possible intracodon recombination breakpoints which resulted in new amino acids at these positions. The almost continuous sequence affiliations within the variants of IG44855, Schomburgk, and IG44857 (upper); PI289605, PI330550, and PI190945 (middle); and PI573523 and IG44878 (bottom) are boxed. Sequence patches of at least three consecutive IPS that deviate from the consensus sequence and are shared between at least two $\mathrm{Sr} 22$ variants are highlighted by black and gray boxes. Patches shared with IG44855, Schomburgk, IG44857, PI355523, PI272557, Westonia, PI289605, and PI330550 are shown by white letters in black boxes. Patches shared with all variants except PI355523, Westonia, and PI352504, are highlighted by gray boxes. Cons = consensus sequence (modal value shared by more than 1 residue is indicated by "+" symbol in the display for the simple reason that it is not possible to display multiple characters in a single character space); dots indicate nucleotides identical to the consensus and dashes indicate gaps in the alignment. 
infection type similar to the equivalent undomesticated synthetic construct (PC132), confirming that the domestication process had not altered gene function (Table 2; Fig. 4).

Golden Gate-based constructs using the same Sr33 regulatory sequences were then developed for $\mathrm{Sr} 22$ alleles from accessions PI190945 (construct PC130) and PI573523 (construct PC146), which had been postulated to carry functional and nonfunctional $\mathrm{Sr} 22$ alleles, respectively (Table 3) (Rouse and Jin 2011a). Ten independent $T_{0}$ families were again tested for each construct with plants containing construct PC130 resistant to $P$. graminis f. sp. tritici race $98-1,2,3,5,6$, whereas plants carrying construct PC146 were susceptible (Table 2; Fig. 4). Based on this result, we designated the resistant allele as $\mathrm{Sr} 22$ and the susceptible allele as $s r 22$. Finally, we produced two constructs that expressed the Schomburgk Sr22 (PC126) and PI573523 sr22 (PC131) alleles, respectively, each under the regulatory control of a maize polyubiquitin promoter (Table 1). In total, $10 \mathrm{~T}_{0}$ families containing PC126 showed resistance against $P$. graminis f. sp. tritici race 98-1,2,3,5,6 (Table 2; Fig. 4). No appreciable difference in resistance was observed when the Schomburgk $S r 22$ allele was expressed with the maize polyubiquitin promoter compared with its endogenous regulatory sequences. Therefore, the maize polyubiquitin promoter can also be used to express functional Sr22-mediated resistance. The $10 \mathrm{~T}_{0}$ families containing construct $\mathrm{PC} 131$ were also tested with $P$. graminis f. sp. tritici race 98-1,2,3,5,6 (Table 2; Fig. 4), where a marginal decrease in susceptibility, from 4 to $3+$, was observed compared with Fielder transgenics expressing the wild-type $s r 22$ PI573523 sequence (Table 2; Fig. 4).

\section{Sr22 wheat transgenics confer resistance against $P$. graminis f. sp. tritici race TTKSK (Ug99).}

$\mathrm{Sr} 22$ is a valuable resistance gene conferring effective resistance against the virulent African $P$. graminis f. sp. tritici race TTKSK, also known as Ug99 (Singh et al. 2006). To confirm that $S r 22$ and its allele in PI190945 is sufficient to confer resistance against $\mathrm{Ug} 99$, we isolated homozygous $\mathrm{T}_{2}$ lines carrying either Schomburgk (PC126, PC127, PC128, and PC103) or PI190945-derived Sr22 gene constructs (PC129 and $\mathrm{PC} 130)$. These $\mathrm{T}_{2}$ lines were found to confer resistance against P. graminis f. sp. tritici race TTKSK (Table 4; Fig. 5).

\section{DISCUSSION}

Disease resistance genes can occur as simple single-gene loci with allelic variation between accessions, or as complex multigene clusters containing related paralogs with scope for copy number variation between accessions. These configurations enable new alleles and genes to be generated by intergenic or intragenic recombination. For the $S r 22$ gene locus studied here, we uncovered evidence for both of these configurations in grasses.

Through a comprehensive phylogenetic analysis, we found that the $S r 22$ gene locus exhibits a clustered distribution in the grass species $H$. vulgare, $A$. atlantica, and $A$. eriantha. The expansions in these species in the Triticeae and Poeae lineages are likely to have happened independently, as indicated by the Hordeum and Avena Sr22 orthologs resolving into separate clades (Fig. 1B). Although the orthology relationships between these Poeae and Triticeae Sr22 loci are clear, the regions containing the Avena $S r 22$ orthologs exhibit very little synteny to the Triticeae $S r 22$ genomic regions, suggesting that the $S r 22$ orthologs in these two clades undertook vastly different trajectories since these lineages last shared a common ancestor.

On the other hand, analysis of the $S r 22$ locus in wheat and its wild relatives revealed single-copy orthologs located on chromosome 7 in T. aestivum, T. turgidum, T. diccocoides, Aegilops tauschii, and T. urartu (Fig. 2). Therefore, this locus appears to have remained as a simple, single-gene locus in wheat species since the separation of the A, B, and D lineages 7 million years ago (Marcussen et al. 2014). This physical organization in

Table 1. List of binary constructs with $\operatorname{Sr} 22$ variants $^{\mathrm{a}}$

\begin{tabular}{|c|c|c|c|c|c|}
\hline Name & ID & Sr22 variant & Promoter & Terminator & Addgene \\
\hline pBW_0001 & PC126 & Schomburgk & Maize ubiquitin & Sr22_Schomburgk & 102833 \\
\hline pBW_0002 & PC127 & Schomburgk & Sr33 & Sr33 & 102834 \\
\hline pBW_0003 & PC128 & Schomburgk & Sr33 & Sr22_Schomburgk & 102835 \\
\hline pBW_0004 & PC130 & PI190945 & Sr33 & Sr33 & 102836 \\
\hline pBW_0005 & PC131 & PI573523 & Maize ubiquitin & Sr22_Schomburgk & 102837 \\
\hline pBW_0006 & PC132 & Schomburgk & Sr33 & $\operatorname{Sr} 33$ & 102838 \\
\hline pBW_0007 & PC146 & PI573523 & Sr33 & Sr33 & 102839 \\
\hline$\ldots$ & $\mathrm{PC} 103^{\mathrm{c}}$ & Schomburgk & Sr22_Schomburgk & Sr22_Schomburgk & $\mathrm{SP}^{\mathrm{d}}$ \\
\hline$\ldots$ & PC129 & PI190945 & Sr22_PI190945 & Sr22_PI190945 & $\mathrm{SP}^{\mathrm{d}}$ \\
\hline
\end{tabular}

${ }^{a}$ All constructs are in $\mathrm{pVecBarII}$ vector with phosphinothricin as plant resistance.

b Synthesized as native, undomesticated gene.

c Published by Steuernagel et al. (2016).

d Available from Sambasivam Periyannan upon request.

Table 2. Stem rust infection assays with Australian Puccinia graminis f. sp. tritici race 98-1,2,3,5,6 on $S r 22$ variant $\mathrm{T}_{0}$ families ${ }^{\mathrm{a}}$

\begin{tabular}{|c|c|c|c|c|c|c|c|c|c|c|c|}
\hline Plant ID & Line & Plant A & Plant B & Plant C & Plant D & Plant E & Plant F & Plant G & Plant $\mathrm{H}$ & Plant I & Plant J \\
\hline PC126 & PC126_T1 & $2=$ & $2=$ & $2=$ & $2=$ & $2=$ & $2=$ & $2=$ & $2=$ & $2=$ & $2=$ \\
\hline PC127 & PC127_T1 & $2=$ & $2=$ & $2=$ & $2=$ & $2=$ & $2=$ & $2=$ & $2=$ & $2=$ & $2=$ \\
\hline PC128 & PC128_T1 & $2=$ & $2=$ & $2=$ & $2=$ & $2=$ & $2=$ & $2=$ & $2=$ & $2=$ & $2=$ \\
\hline PC130 & PC130_T1 & $2=$ & $2=$ & $2=$ & $2=$ & $2=$ & $2=$ & $2=$ & $2=$ & $2=$ & $2=$ \\
\hline PC131 & PC131_T1 & $3+$ & $3+$ & $3+$ & $3+$ & $3+$ & $3+$ & $3+$ & $3+$ & $3+$ & $3+$ \\
\hline PC132 & PC132_T1 & $2=$ & $2=$ & $2=$ & $2=$ & $2=$ & $2=$ & $2=$ & $2=$ & $2=$ & $2=$ \\
\hline PC146 & PC146_T1 & 4 & 4 & 4 & 4 & 4 & 4 & 4 & 4 & 4 & 4 \\
\hline $\mathrm{PC} 103^{\mathrm{b}}$ & PC103_T1 & $2-$ & $2-$ & $2-$ & $2-$ & $2-$ & $2-$ & NA & NA & NA & NA \\
\hline Fielder & $\mathrm{S}$ control $^{\mathrm{c}}$ & 4 & 4 & 4 & 4 & 4 & 4 & 4 & 4 & 4 & 4 \\
\hline
\end{tabular}

a NA = not available.

b Published by Steuernagel et al. (2016).

c Susceptible control. 
wheat species is similar to the Arabidopsis Rpml (Stahl et al. 1999) and RPP13 (Bittner-Eddy et al. 2000) genes but in contrast to most resistance genes which are members of large clusters of gene paralogs such as the tomato $C f-4$ and $C f-9$ genes at the Milky Way locus (Parniske et al. 1997), the flax $M$ locus (Anderson et al. 1997), the Arabidopsis RPP5 locus (Noël et al. 1999), the RGC2 locus in lettuce (Kuang et al. 2004), and the maize Rpl locus (Sun et al. 2001). In the case of the complex barley Mla (powdery mildew) resistance locus (Wei et al. 2002), stem rust resistance occurs in haplotypes derived from both Aegilops tauschii (Sr33) (Periyannan et al. 2013) and rye $(\mathrm{Sr} 50)$ (Mago et al. 2015). By analogy, it is conceivable that Sr22 variants from outside the genus Triticum also provide stem rust resistance, although this hypothesis was not tested in the present study.

Nucleotide sequence alignment of the 15 Sr22 alleles showed that the greatest sequence variation occurs in the leucine-rich repeat (LRR) domain. This is consistent with its proposed role in pathogen recognition specificity, which is believed to explain the higher degree of diversifying selection typically found in this part of the protein (Dodds et al. 2006; Krasileva et al. 2010). Comparison of these nucleotide sequences also showed evidence of extensive historical recombination between alleles based on obvious mosaic patterns of sequence conservation (Fig. 3). This "gene shuffling" most likely resulted from multiple, iterative intragenic sequence exchange events and is proposed to be a major mechanism in generating sequence variation from which new resistance specificities are selected during host-pathogen coevolution (Parniske et al. 1997). Because the wheat $\mathrm{Sr} 22$ locus is physically simple, with only a single gene member, the observed sequence variation between alleles is most likely due to intraallelic recombination, as observed for the Arabidopsis RACl and RPP13 genes (Serra et al. 2018). Intraallelic recombination can also be unequal, particularly between tandem repeat domains such as in the LRRs (Dixon et al. 1998).

From 22 accessions that were initially identified, 8 contain the same $S r 22$ allele. This may indicate that they were derived from a common parent (which was erroneously given different accession numbers) or that there is conservation of sequence at this locus among genetically distinct accessions. The generation of additional genotype data outside of the $\mathrm{Sr} 22$ locus would be required to further elucidate this question.

In this study, we confirmed the function of three $S r 22$ alleles by generating and phenotyping transgenic wheat plants (Figs. 4 and 5). As postulated, two of these $S r 22$ alleles were found to confer resistance against $P$. graminis $\mathrm{f}$. sp. tritici race 981,2,3,5,6 and TTKSK. We used multisegment Golden Gate assembly (Weber et al. 2011) to rapidly generate constructs and negate potential expression differences that could arise from variation in allele regulatory sequences. We used the Sr22 promoter and terminator, $S r 33$ promoter and terminator, and maize ubiquitin promoter to test three allelic variants of $S r 22$. All of these regulatory elements were undomesticated, apart from the Sr22 terminator. In the future, these modular components can be used for allele mining and functionality testing of candidate stem rust resistance genes identified by map-based approximation (e.g., TACCA [Thind et al. 2017]), mutational genomics (e.g., MutRenSeq [Steuernagel et al. 2016] and
A

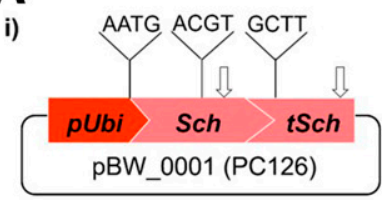

iii)

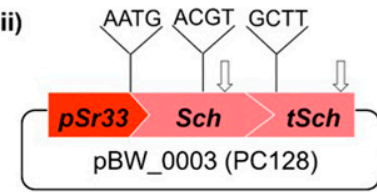

v)

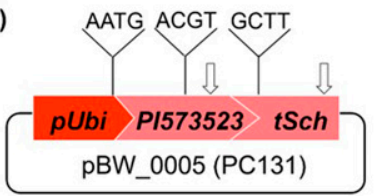

vii)

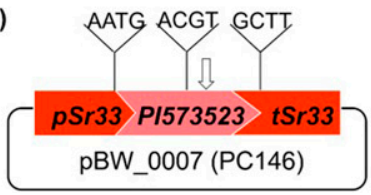

ii)

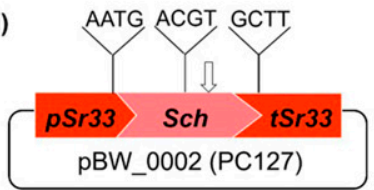

iv)

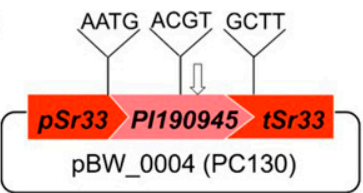

vi)

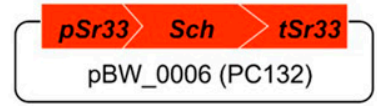

viii)

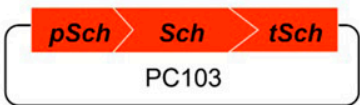

B

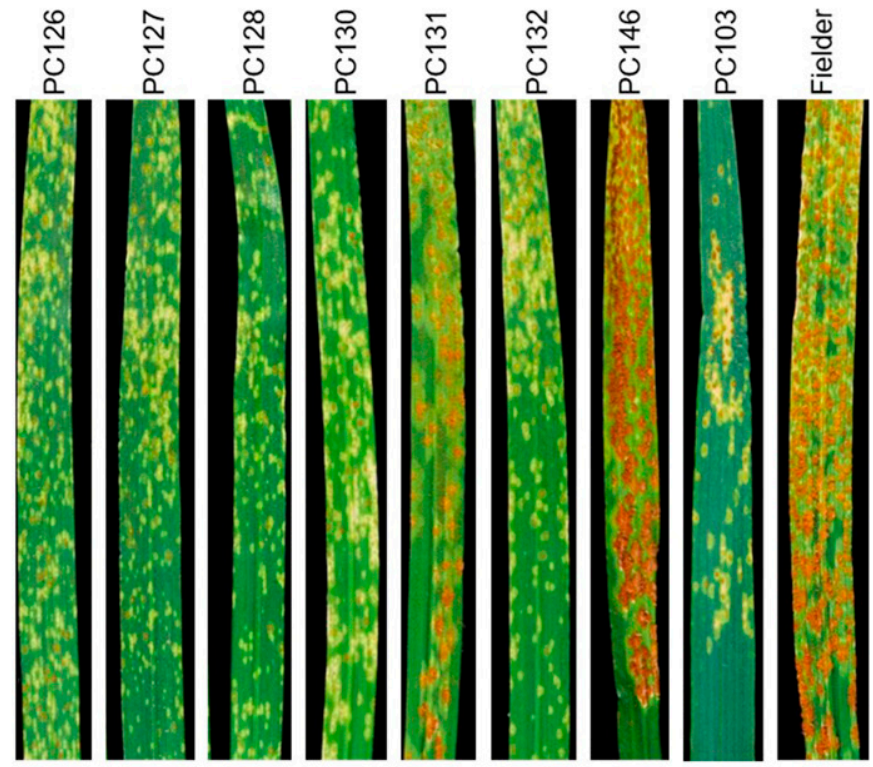

Fig. 4. Phenotypic reaction of transgenic Sr22 variants against Australian Puccinia graminis f. sp. tritici race 98-1,2,3,5,6. A, Schematic overview (not shown to scale) of the constructs used in stem rust disease resistance assays. Binary construct containing (i) BsaI-domesticated $S r 22$ Schomburgk (Sch) driven by $5^{\prime}$ maize ubiquitin $(U b i)$ and $B s a I$-domesticated $3^{\prime} S r 22$ regulatory elements $(t S c h)$, respectively; (ii) BsaI-domesticated $S r 22$ Schomburgk driven by $5^{\prime}$ and $3^{\prime}$ Sr33 regulatory elements ( $p S r 33$ and $t S r 33$, respectively); (iii) BsaI-domesticated Sr22 Schomburgk driven by $5^{\prime} S r 33$ and BsaI-domesticated $3^{\prime} S r 22$ regulatory elements, respectively; (iv) BsaI-domesticated Sr22 PI190945 driven by 5' and 3' Sr33 regulatory elements; (v) BsaI-domesticated sr22 PI573523 driven by $5^{\prime}$ maize ubiquitin and BsaI-domesticated $3^{\prime} S r 22$ regulatory elements, respectively; (vi) native $S r 22$ Schomburgk driven by $5^{\prime}$ and $3^{\prime} S r 33$ regulatory elements; (vii) BsaI-domesticated $s r 22$ PI573523 driven by $5^{\prime}$ and $3^{\prime} S r 33$ regulatory elements; and (viii) native $S r 22$ Schomburgk driven by its $5^{\prime}$ and $3^{\prime}$ regulatory elements ( $p S c h$ and $t S c h$, respectively). Nonnative four-nucleotide linkers in pBW_0001, pBW_0002, pBW_0003, pBW_0004, pBW_0005, and pBW_0007 were introduced immediately before the start codon, in the middle of the coding region, and immediately after the stop codon. White arrows correspond to the removed BsaI sites. B, Stem rust infection assays using the Australian $P$. graminis f. sp. tritici race 98-1,2,3,5,6 on representative seedlings of primary transgenic lines $\left(\mathrm{T}_{0}\right)$ of $S r 22$ variants and comparison with the susceptible control Fielder. 
MutChromSeq [Sánchez-Martín et al. 2016]), or association genetics (e.g., AgRenSeq [Arora et al. 2019]).

\section{MATERIALS AND METHODS}

Phylogenetic analysis to identify $\mathbf{S r} 22$ orthologs.

The coding sequence of the $S r 22$ gene from wheat cultivar Schomburgk was translated and the predicted amino acid sequence was used as a query for BLASTP searches against the predicted protein sequences derived from the genomes and transcriptomes of 80 plant species (Supplementary File S1). The taxonomic status of the 80 plant species used here was determined using the Angiosperm Phylogeny Group IV system APG IV (The Angiosperm Phylogeny Group et al. 2016) (Tropicos database and the Angiosperm Phylogeny Website) for non-Poaceae and, for Poaceae species, the system presented by Soreng et al. (2017) was used. A representative phylogeny of the different plant clades studied here (Fig. 1A) was made using TreeGraph version 2 (Stöver and Müller 2010) and edited in Adobe Illustrator. Predicted protein sequences for the genomes used were downloaded from the respective genome database (Supplementary File S1) whereas, for the transcriptomes used here, predicted proteins were obtained using TransDecoder version 5.5.0 (Haas et al. 2013). The top 25 hits from each species in the genome dataset and the top 3,000 hits from the combined transcriptome data were obtained and aligned with MUSCLE version 3.8.425 (Edgar 2004) using default parameters. An initial tree was constructed with this alignment as input using FastTree version 2.1.11 (Price et al. 2010) with the WAG model to identify putative $S r 22$ homologs. In the above preliminary phylogeny, the $S r 22$ clade was identified and the tree was manually curated to retain only the longest isoform for genes where multiple isoforms were picked up by the BLAST searches. Because no orthologs of $S r 22$ were found in the proteomes of Aegilops tauschii and T. diccocoides, a further search in the genomes of these species was conducted as detailed in the "Manual identification of Sr22 homologs" section below. BLASTP searches on the pangenomes of Brachypodium spp. and rice were also conducted using the translated coding sequences of the wheat Schomburgk $\mathrm{Sr} 22$ gene to check whether any $\mathrm{Sr} 22$ orthologs could be found in these pangenomes. The top 50 hits from each pangenome were combined with the sequences obtained from the Triticeae, rice, and Brachypodium genomes in the initial search and aligned using MUSCLE version 3.8.425, and a phylogeny was constructed with IQTree version 1.6.10 (Nguyen et al. 2015) using default options. The JTT+F+R8 evolutionary model was found to best explain the evolution of these sequences, and branch support was assessed using 1,000 bootstrap replicates for UFBoot and SH-aLRT.

In $H$. vulgare, several proteins orthologous to $\mathrm{Sr} 22$ with consecutive identifications (IDs) were found. To ensure that these were not artifacts of the gene prediction process, the $H$. vulgare genomic region containing these genes was manually curated (as detailed in the "Manual curation of syntenic region in $H$. vulgare" section below) to collect only high confidence gene annotations. The resultant curated $\mathrm{Sr} 22$ homologous sequences were then used to construct an alignment using MUSCLE version 3.8.425. The

Table 3. Stem rust resistance score for selected diploid accessions of Triticum boeoticum and T. monococcum and hexaploid wheat cultivars ${ }^{\text {a }}$

\begin{tabular}{|c|c|c|c|c|c|c|c|c|c|}
\hline \multirow[b]{3}{*}{ Species, accession ( $\mathrm{Sr} 22$ allele) } & \multirow[b]{3}{*}{$\operatorname{Sr} 22^{\mathbf{b}}$} & \multicolumn{8}{|c|}{ Infection type } \\
\hline & & \multicolumn{3}{|c|}{ Australian Puccinia graminis f. sp. tritici } & \multicolumn{5}{|c|}{ Rouse and Jin 2011b } \\
\hline & & $17-1,2,3,7=142$ & $98-1,2,3,5,6$ & $194-1,2,3,5,6$ & TRTTF & TTKSK & TTTTF & QFCSC & MCCFC \\
\hline \multicolumn{10}{|l|}{ T. monococcum } \\
\hline PI289605 & + & NA & NA & NA & $2-$ & $2-$ & $2-$ & $; 1$ & $; 1$ \\
\hline PI355523 & - & NA & NA & NA & $3+$ & 3 & 4 & $3+$ & 4 \\
\hline PI330550 & + & NA & NA & NA & 2 & 2 & $2 / 2+$ & $; 1-$ & $; 1$ \\
\hline PI190945 & + & NA & NA & NA & 1 & 1 & $2-;$ & $; 1-$ & $; 1$ \\
\hline W3534 & + & $22-$ & NA & NA & NA & NA & NA & NA & NA \\
\hline DV92 & - & NA & NA & NA & NA & NA & NA & $3+$ & NA \\
\hline P1573523 & - & NA & NA & NA & $2-$ & ;N & 2 & ;2- & $; 1-$ \\
\hline PI272557 & - & NA & NA & NA & $3+$ & 4 & 4 & 4 & 4 \\
\hline PI362553 & + & NA & NA & NA & $2-$ & 1 & $2-$ & $; 2=$ & $; 1$ \\
\hline PI362554 & + & NA & NA & NA & $2-$ & $; 1$ & $2-$ & ;2- & $; 1$ \\
\hline PI355522 & + & NA & NA & NA & 1 & $; 1$ & $1 ; / 2-$ & ;12- & $; 1$ \\
\hline \multicolumn{10}{|l|}{ T. boeoticum } \\
\hline IG44855 & + & $2=$ & $2=$ & $1+$ & NA & NA & NA & NA & NA \\
\hline IG44857 & + & $2=$ & $2-$ & NA & NA & NA & NA & NA & NA \\
\hline IG44921 & + & $2=$ & $2=$ & $1+$ & NA & NA & NA & NA & NA \\
\hline IG44878 & - & $3+$ & NA & NA & NA & NA & NA & NA & NA \\
\hline PI352504 & + & NA & NA & NA & 2 & $2-$ & 2 & ;2- & $; 1$ \\
\hline IG44870 & + & $2=$ & 1 & 1 & NA & NA & NA & NA & NA \\
\hline IG44866 & + & $2=$ & 1 & $1-$ & NA & NA & NA & NA & NA \\
\hline IG44868 & + & $2=$ & NA & NA & NA & NA & NA & NA & NA \\
\hline IG44919 & + & $2=$ & $2=$ & NA & NA & NA & NA & NA & NA \\
\hline \multicolumn{10}{|l|}{ T. aestivum } \\
\hline Westonia & - & $3+$ & NA & NA & NA & NA & NA & NA & NA \\
\hline Schomburgk & + & $2-$ & NA & NA & NA & NA & NA & NA & NA \\
\hline GM Schomburgk ${ }^{\mathrm{c}}$ & $\ldots$ & NA & $2-$ & NA & NA & 2 & NA & NA & NA \\
\hline GM PI190945 & $\ldots$ & NA & $2={ }^{e}$ & NA & NA & $2^{f}$ & NA & NA & NA \\
\hline GM PI573523 & $\ldots$ & NA & 4 & NA & NA & NA & NA & NA & NA \\
\hline \multicolumn{10}{|l|}{${ }^{\mathrm{a}} \mathrm{NA}=$ not available. } \\
\hline \multicolumn{10}{|c|}{ b $S r 22$ postulation. } \\
\hline \multirow{2}{*}{\multicolumn{10}{|c|}{ c Genetically modified (GM) (i.e., transgenic) Fielder with Schomburgk Sr22 allele. Driven by native regulatory elements and published by Steuernagel et al. }} \\
\hline & & & & & & & & & \\
\hline \multicolumn{10}{|c|}{ d GM Fielder with PI190945 Sr22 allele. } \\
\hline \multicolumn{10}{|c|}{ e Driven by $S r 33$ regulatory elements. } \\
\hline \multicolumn{10}{|c|}{${ }^{f}$ Driven by native regulatory elements. } \\
\hline g Driven by $S r 33$ regulatory elem & & & & & & & & & \\
\hline
\end{tabular}

Vol. 33, No. $11,2020 / 1293$ 
conserved NB-ARC regions in these sequences were extracted using the procedure detailed below. First, the sequences were aligned using HMMER3 HMMALIGN (Eddy 2009) to a previously published NB-ARC1-ARC2 HMM (Bailey et al. 2018) and any sites with greater than $95 \%$ gaps in the alignment were removed. Only sequences with more than 200 amino acid residues corresponding to this region in the alignment were then retained. The NB-ARC1-ARC2 regions from a curated set of $38 R$-gene

Table 4. Stem rust infection assays with Puccinia graminis f. sp. tritici race TTKSK on $\operatorname{Sr} 22$ variants $\mathrm{T}_{2}$ families ${ }^{\mathrm{a}}$

\begin{tabular}{|c|c|c|c|c|}
\hline \multirow[b]{2}{*}{ Event, line } & \multicolumn{2}{|c|}{ Rep 1} & \multicolumn{2}{|c|}{$\operatorname{Rep} 2$} \\
\hline & $N$ & IT & $N$ & IT \\
\hline PC103-1 & 5 & 2 & 5 & 2 \\
\hline PC103-2 & 5 & 2 & 5 & 2 \\
\hline PC103-4 & 5 & $22-$ & 4 & $22-$ \\
\hline PC103-5ab & 5 & $3+$ & 5 & $3+$ \\
\hline PC126-2 & 5 & $22+$ & 5 & $2-$ \\
\hline PC126-3 & 5 & $2-$ & 5 & $2-$ \\
\hline $\mathrm{PC} 126-5^{\mathrm{b}}$ & 5 & $3+$ & 5 & $3+$ \\
\hline PC127-2 & 5 & $2-$ & 5 & $22-$ \\
\hline PC127-3 & 5 & $2-$ & 5 & $2-$ \\
\hline PC127-5 & 5 & $2-$ & 5 & $2-$ \\
\hline PC127-6 ${ }^{\mathrm{b}}$ & 5 & $3+$ & 5 & $3+$ \\
\hline PC128-5 & 4 & $2-$ & 5 & $22-$ \\
\hline PC128-6 & 4 & $2-$ & 5 & $22-$ \\
\hline $\mathrm{PC} 128-7^{\mathrm{b}}$ & 4 & $33+$ & 4 & $33+$ \\
\hline PC129-4 & 5 & 2 & 5 & 2 \\
\hline PC129-5 & 5 & 2 & 5 & $22-$ \\
\hline PC129-6 ${ }^{\mathrm{b}}$ & 5 & $33+$ & 5 & $33+$ \\
\hline $\mathrm{PC} 130-2^{\mathrm{c}}$ & 5 & $2-$ & 4 & $22-$ \\
\hline $\mathrm{PC} 130-4^{\mathrm{c}}$ & 3 & $22-$ & 5 & $22-$ \\
\hline Fielder & 5 & $3+$ & 5 & $3+$ \\
\hline
\end{tabular}

${ }^{\text {a }} N=$ Number of tested plants and IT $=$ infection type.

b Null lines.

c Published by Steuernagel et al. (2016). proteins were added to provide outgroup references for the final phylogeny and an alignment was constructed using HMMER3 HMMALIGN (Eddy 2009) against the NB-ARC1-ARC2 HMM.

Based on this alignment, we then constructed a phylogenetic tree (Supplementary File S2) using the default options in IQTree version 1.6.10 (Nguyen et al. 2015) and assessing branch support with 1,000 bootstrap replicates for UFBoot and SH-aLRT using the JTT+F+R10 evolutionary model, which was found to be the best fit for these sequences. The sequences from the $S r 22$ clade from this tree and the curated $R$-gene dataset (Bailey et al. 2018) were extracted and a phylogeny was generated (Fig. 1B) as described above using IQTree using the JTT+I+G4 evolutionary model, which was found to be the best fit for these sequences. The alignments used to generate the phylogenetic trees can be found in figshare.

\section{Manual curation of syntenic region in $\boldsymbol{H}$. vulgare.}

For the genomic region on chromosome $7 \mathrm{H}$ in $H$. vulgare containing $\mathrm{Sr} 22$ orthologs, several gene annotations were not supported by coding sequence annotations or spanned multiple coding sequences over a length of $\geq 100 \mathrm{~kb}$. In addition, some annotations overlapped with respect to genomic positions. To obtain reliable gene predictions, the region was manually curated to keep only those genes with coding sequence support. Following this, the longest isoform for a given gene was used. If overlapping coding sequences were found to be of the same length, those containing start and stop codons were retained. The genomic region was also parsed using NLR-Annotator to identify loci in the region that potentially coded for an NLR (Steuernagel et al. 2018) (github NLR Annotator). A coding sequence was designated as encoding an NLR (full or partial) only if supported by NLR-Annotator. For Sr22 homologs, if two overlapping coding sequences were of the same length and both had start and stop codons, the one with higher amino acid sequence identity to $\mathrm{Sr} 22$ was selected.
A

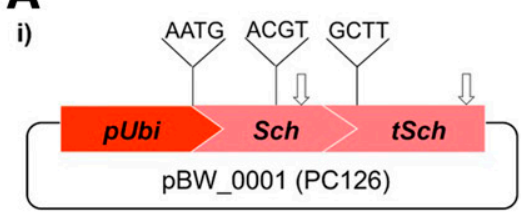

ii)

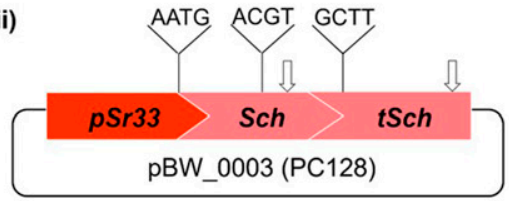

v)

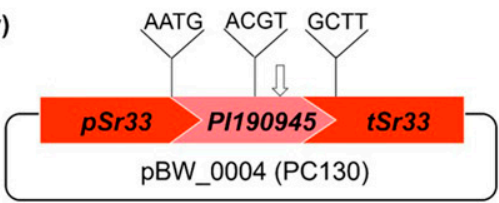

i)

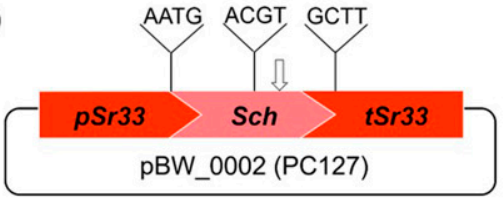

iv)

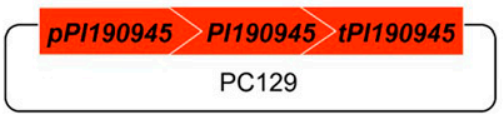

vi)

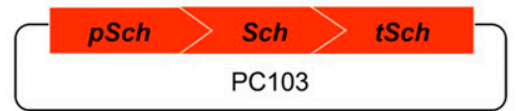

B

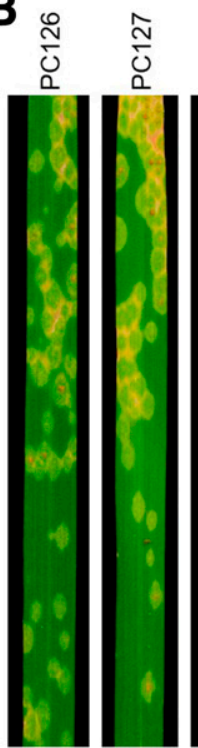

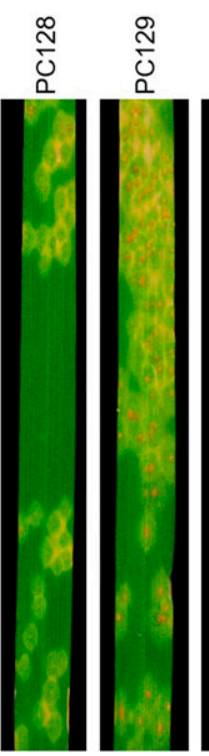
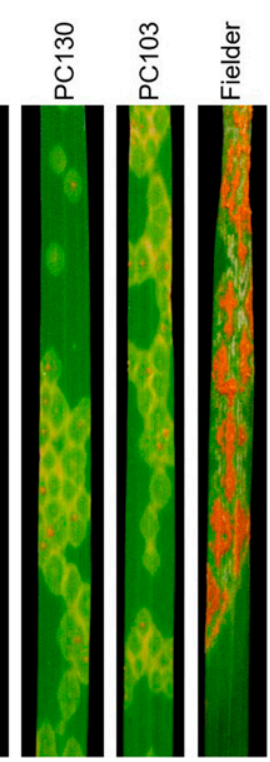

Fig. 5. Phenotypic reaction of transgenic Sr22 variants against Puccinia graminis f. sp. tritici race TTKSK. A, Schematic overview (not shown to scale) of the constructs used in stem rust resistance assays. Binary construct containing (i) BsaI-domesticated Sr22 Schomburgk driven by $5^{\prime}$ maize ubiquitin and BsaIdomesticated 3' Sr22 regulatory elements, respectively; (ii) BsaI-domesticated Sr22 Schomburgk driven by 5' and 3' Sr33 regulatory elements; (iii) BsaIdomesticated $S r 22$ Schomburgk driven by 5' Sr33 and BsaI-domesticated 3' Sr22 regulatory elements, respectively; (iv) native $S r 22$ PI190945 driven by its $5^{\prime}$ and 3' regulatory elements; (v) BsaI-domesticated Sr22 PI190945 driven by 5' and 3' Sr33 regulatory elements; and (vi) native Sr22 Schomburgk driven by its $5^{\prime}$ and $3^{\prime}$ regulatory elements. Nonnative four-nucleotide linkers in pBW_0001, pBW_0002, pBW_0003, and pBW_0004 were introduced immediately before the start codon, in the middle of the coding region, and immediately after the stop codon. White arrows correspond to the removed $B$ saI sites. B, Stem rust infection assays using the $P$. graminis $\mathrm{f}$. sp. tritici race TTKSK on representative seedlings of $\mathrm{T}_{2}$ lines of $S r 22$ variants and comparison with the susceptible control Fielder. 


\section{Manual identification of $\mathrm{Sr} 22$ homologs}

\section{in Aegilops tauschii, T. diccocoides, and T. urartu.}

For Aegilops tauschii and T. diccocoides, orthologs of $\mathrm{Sr} 22$ were not detected when examining the predicted protein sequences. Using the $\mathrm{Sr} 22$ genomic sequence (from Schomburgk) as a query, we searched the genomes of these two species using BLASTN. The top hits were found to be from genomic regions on chromosome 7 in each of these species in their respective subgenomes. To obtain the corresponding $\mathrm{Sr} 22$ ortholog from these regions, splice sites and start or stop codons were manually annotated through alignment and comparison with the $S r 22$ coding and genomic sequences. In Aegilops tauschii, the annotation overlapped with the gene annotation with ID AET7Gv21218700. Thus, the Sr22 homolog was renamed to AET7Gv21218700_[corrected] (reflected in nomenclature in Supplementary File S1).

For T. urartu, two proteins with consecutive gene IDs were predicted to be orthologous to $S r 22$. Examination of the alignment of these proteins to the $S r 22$ protein sequence showed that, whereas one of these sequences aligned to the $\mathrm{N}$ terminal region of $S r 22$, the other aligned to the C-terminal region. The genes encoding these proteins were found to be immediately adjacent on the genome, separated by a stretch of ambiguous bases (NNNNNNs). Thus, these two loci were determined as corresponding to a single NLR locus, fragmented due to assembly errors (reflected in nomenclature in Supplementary File S1).

\section{Synteny analysis of genomic regions containing Sr22 homologs.}

Ten genes on either side flanking the genomic regions containing $S r 22$ orthologs in the genomes of T. aestivum, T. turgidum, T. diccocoides, Aegilops tauschii, and T. urartu were obtained using the neighborhood conservation feature on Gramene. In H. vulgare 'Morex', A. atlantica, and A. eriantha, because several $S r 22$ orthologous copies were identified, 10 genes flanking the first and last orthologous copy as well as the genes in between these two copies were obtained. The predicted functional annotation of these genes was determined using the model species homolog prediction feature in Gramene (for only $H$. vulgare), BLASTX searches against the NCBI nr protein database, and through domain identification using InterProScan. We also used NLR-Annotator to check whether any of these genes were either full-length or partial NLRs. For the $H$. vulgare 'Golden Promise', H. vulgare var. nudum, and $H$. spontaneum synteny searches, $1 \mathrm{Mb}$ of sequence around the top BLASTN hit to the H. vulgare 'Morex' Sr22containing region was analyzed. The predicted functional annotation was determined in the same way as described above for Morex.

For B. distachyon and $O$. sativa, proteins orthologous to $S r 22$ could not be located. To check whether these genomes contained any regions exhibiting conservation of microsynteny to the genomic regions containing $S r 22$ in the tribe Triticeae, the genes flanking the $S r 22$ ortholog in chromosome 7D in T. aestivum 'Chinese Spring' were used. We selected 20 genes in the neighborhood of the $S r 22$ ortholog in T. aestivum chr7D, 10 on either side. For each of these genes, we determined its homolog in $O$. sativa and $B$. distachyon using Gramene. We then examined the location of these homologs to check whether homologs of the $S r 22$ gene neighborhood were found in a similar contiguous genomic stretch in these species. Functional identities of these homologs were obtained using the model species homolog prediction feature in Gramene, BLASTX searches against the NCBI nr protein database, and through domain identification using InterProScan. The regions showing microsynteny were analyzed with NLR-Annotator to check for the presence of NLRs.

\section{Acquisition and verification of $\boldsymbol{S r} 22$ sequence variants.}

In total, 14 Sr22 sequence variants were previously identified in Steuernagel et al. (2016) by PCR screening and sequencing of accessions of $T$. boeoticum (and its domesticated form T. monococcum), which had been postulated to carry either functional $(S r 22)$ or nonfunctional ( $s r 22)$ alleles of $S r 22$. In this study, further PCR screening of an additional 25 accessions and sequencing revealed another eight different sequences from these species.

Accessions of $T$. boeoticum were assessed for seedling infection types in response to $P$. graminis $\mathrm{f}$. sp. tritici isolates 59KS19 (race MCCFC), 04KEN156/04 (race TTKSK, syn. Ug99), 09CA115-2 (race BCCBC), and 06ND76C (race QFCSC) according to previously described methods (Hundie et al. 2019).

\section{Nucleotide sequence analysis of $\mathrm{Sr} 22$ variants.}

Nucleotide sequence alignment of $\mathrm{Sr} 22$ variants was performed using Clustal Omega (Sievers et al. 2011) with the default parameters, except the order in which the sequences appear in the final alignment was set to "input sequence order". The alignment output was visualized and analyzed using Jalview version 2 (Waterhouse et al. 2009). Only informative polymorphic sites are shown in the final alignment, defined as those sites where two or more alternative nucleotides occur in at least two sequences within the alignment.

\section{Generation of binary constructs carrying $\mathrm{Sr} 22$.}

The maize ubiquitin and the $S r 33$ promoter regions were used for designing $\mathrm{Sr} 22$ chimeric constructs. Sr 22 coding regions (sequence from START to STOP codon, including both exons and introns) from three different sources, including $\mathrm{Sr} 22$ Schomburgk, Sr22-PI190945, and sr22-PI573523, were used for the designs. For the simplicity of construct synthesis, the coding regions were divided into two sections; namely, coding region 1 and 2. The $S r 22$-Schomburgk and the $S r 33$ terminator regions were used in some constructs. All of these modular components were synthesized by a commercial DNA synthesis provider (Life Technologies Ltd.). The synthesized components were assembled by Golden Gate cloning (Weber et al. 2011) into the toolkit vector pICH47732 (Weber et al. 2011), then transferred to pVecBARII (a derivative of pWBvec8 in which the $35 \mathrm{~S}$ hygromycin gene has been replaced with a $35 \mathrm{~S}$ BAR selectable marker gene) (Wang et al. 1998) as NotI fragments. Prior to synthesis, all native $B s a I$ sites were domesticated (i.e., removed by editing) without changing the predicted amino acid coding sequence within the exons of the coding regions, and without changing the intron splice donor or acceptor sites. The domestication was performed using the program Genious version 7.1.7. All modular components were domesticated and synthesized as level 0 modules by introducing $B s a$ I sites at the start and at the end of each module. In addition to introduction of flanking NotI sites, the sequence AATG was added to link promoter and coding regions and the sequence GCTT was added to link coding regions and terminators. The sequence ACGT was added to link coding region 1 and 2. The sequences GGAG and CGCT were added to link left and right borders of the vector, respectively. The assembled level 1 module was transferred into the pVecBARII binary vector for wheat transformation. In addition, a gene which was not domesticated by $B s a \mathrm{I}$ site removal and was composed of the $S r 33$ promoter fused to the $S r 22$ coding region fused to the $S r 33$ terminator, was designed and synthesized. All binary plasmids containing the desired insert were transformed by electroporation into Agrobacterium tumefaciens for wheat transformation. 


\section{Wheat transformation, stem rust inoculations, and phenotypic evaluations.}

The Sr22 binary constructs were introduced into wheat cultivar Fielder using the Agrobacterium transformation protocol described by Ishida et al. (2015) and phosphinothricin as a selective agent. Ten independent primary transgenic plants were recovered and grown in an automated growth cabinet with conditions of $16 \mathrm{~h}$ of light and $8 \mathrm{~h}$ of darkness and a constant temperature of $23^{\circ} \mathrm{C}$. The plants were inoculated with the Australian $P$. graminis f. sp. tritici race 98-1,2,3,5,6 (Park 2016), which is virulent on Fielder at the fully developed thirdleaf stage. After $24 \mathrm{~h}$ of incubation in a closed transparent plastic box under high humidity, the plants were restored to the original growth conditions and observed for rust development. Rust infection types were scored 14 days postinoculation.

For all six binary constructs, at least two homozygous $\mathrm{T}_{2}$ transgenic plants were inoculated with the $P$. graminis f. sp. tritici race TTKSK (isolate 04KEN156/04) at the fully developed first leaf stage according to previously described methods for evaluating stem rust seedling infection types (Hundie et al. 2019). Infection types were scored 15 days postinoculation.

\section{ACKNOWLEDGMENTS}

We thank M. Vorontsova for providing valuable guidance on the taxonomic relationships between monocots.

\section{AUTHOR-RECOMMENDED INTERNET RESOURCES}

Angiosperm Phylogeny Website, version 14:

http://www.mobot.org/MOBOT/research/APweb

figshare: https://figshare.com

github NLR Annotator: https://github.com/steuernb/NLR-Annotator

Gramene database: http://www.gramene.org

Tropicos database: https://www.tropicos.org/home

\section{LITERATURE CITED}

Anderson, P. A., Lawrence, G. J., Morrish, B. C., Ayliffe, M. A., Finnegan, E. J., and Ellis, J. G. 1997. Inactivation of the flax rust resistance gene $M$ associated with loss of a repeated unit within the leucine-rich repeat coding region. Plant Cell 9:641-651.

Arora, S., Steuernagel, B., Gaurav, K., Chandramohan, S., Long, Y., Matny, O., Johnson, R., Enk, J., Periyannan, S., Singh, N., Asyraf Md Hatta, M., Athiyannan, N., Cheema, J., Yu, G., Kangara, N., Ghosh, S., Szabo, L. J., Poland, J., Bariana, H., Jones, J. D. G., Bentley, A. R., Ayliffe, M., Olson, E., Xu, S. S., Steffenson, B. J., Lagudah, E., and Wulff, B. B. H. 2019. Resistance gene cloning from a wild crop relative by sequence capture and association genetics. Nat. Biotechnol. 37:139-143.

Bai, J., Pennill, L. A., Ning, J., Lee, S. W., Ramalingam, J., Webb, C. A., Zhao, B., Sun, Q., Nelson, J. C., Leach, J. E., and Hulbert, S. H. 2002. Diversity in nucleotide binding site-leucine-rich repeat genes in cereals. Genome Res. 12:1871-1884.

Bailey, P. C., Schudoma, C., Jackson, W., Baggs, E., Dagdas, G., Haerty, W., Moscou, M., and Krasileva, K. V. 2018. Dominant integration locus drives continuous diversification of plant immune receptors with exogenous domain fusions. Genome Biol. 19:23.

Berlin, A. 2017. Stem rust attacks in Sweden heralds the return of a previously vanquished foe. SLU News, Swedish University of Agricultural Sciences, Uppsala, Sweden.

Bhattacharya, S. 2017. Deadly new wheat disease threatens Europe's crops. Nature 542:145-146.

Bittner-Eddy, P. D., Crute, I. R., Holub, E. B. and Beynon, J. L. 2000. $R P P 13$ is a simple locus in Arabidopsis thaliana for alleles that specify downy mildew resistance to different avirulence determinants in Peronospora parasitica. Plant J. 21:177-188.

Chen, J., Upadhyaya, N. M., Ortiz, D., Sperschneider, J., Li, F., Bouton, C., Breen, S., Dong, C., Xu, B., Zhang, X., Mago, R., Newell, K., Xia, X., Bernoux, M., Taylor, J. M., Steffenson, B., Jin, Y., Zhang, P., Kanyuka, K., Figueroa, M., Ellis, J. G., Park, R. F., and Dodds, P. N. 2017. Loss of AvrSr50 by somatic exchange in stem rust leads to virulence for $\mathrm{Sr} 50$ resistance in wheat. Science 358:1607-1610.
Chen, S., Guo, Y., Briggs, J., Dubach, F., Chao, S., Zhang, W., Rouse, M. N., and Dubcovsky, J. 2018a. Mapping and characterization of wheat stem rust resistance genes SrTm5 and Sr60 from Triticum monococcum. Theor. Appl. Genet. 131:625-635.

Chen, S., Rouse, M. N., Zhang, W., Zhang, X., Guo, Y., Briggs, J., and Dubcovsky, J. 2020. Wheat gene Sr60 encodes a protein with two putative kinase domains that confers resistance to stem rust. New Phytol. 225:948-959.

Chen, S., Zhang, W., Bolus, S., Rouse, M. N., and Dubcovsky, J. 2018b. Identification and characterization of wheat stem rust resistance gene Sr21 effective against the Ug99 race group at high temperature. PLoS Genet. 14:e1007287.

Dixon, M. S., Hatzixanthis, K., Jones, D. A., Harrison, K., and Jones, J. D. G. 1998. The tomato $C f-5$ disease resistance gene and six homologs show pronounced allelic variation in leucine-rich repeat copy number. Plant Cell 10:1915-1925.

Dodds, P. N., Lawrence, G. J., Catanzariti, A. M., Teh, T., Wang, C. I., Ayliffe, M. A., Kobe, B., and Ellis, J. G. 2006. Direct protein interaction underlies gene-for-gene specificity and coevolution of the flax resistance genes and flax rust avirulence genes. Proc. Natl. Acad. Sci. U.S.A. 103:8888-8893.

Dodds, P. N., Lawrence, G. J., and Ellis, J. G. 2001. Six amino acid changes confined to the leucine-rich repeat beta-strand/beta-turn motif determine the difference between the $P$ and $P 2$ rust resistance specificities in flax. Plant Cell 13:163-178.

Eddy, S. R. 2009. A new generation of homology search tools based on probabilistic inference. Pages 205-211 in: Int. Conf. Genome Informatics 23.

Edgar, R. C. 2004. MUSCLE: Multiple sequence alignment with high accuracy and high throughput. Nucleic Acids Res. 32:1792-1797.

Ellis, J., Dodds, P., and Pryor, T. 2000. The generation of plant disease resistance gene specificities. Trends Plant Sci. 5:373-379.

Ellis, J. G., Lawrence, G. J., Luck, J. E., and Dodds, P. N. 1999. Identification of regions in alleles of the flax rust resistance gene $L$ that determine differences in gene-for-gene specificity. Plant Cell 11:495-506.

Fetch, T., Zegeye, T., Park, R. F., Hodson, D., and Wanyera, R. 2016. Detection of wheat stem rust races TTHSK and PTKTK in the Ug99 race group in Kenya in 2014. Plant Dis. 100:1495.

Haas, B. J., Papanicolaou, A., Yassour, M., Grabherr, M., Blood, P. D., Bowden, J., Couger, M. B., Eccles, D., Li, B., Lieber, M., MacManes, M. D., Ott, M., Orvis, J., Pochet, N., Strozzi, F., Weeks, N., Westerman, R., William, T., Dewey, C. N., Henschel, R., LeDuc, R. D., Friedman, N., and Regev, A. 2013. De novo transcript sequence reconstruction from RNA-seq using the Trinity platform for reference generation and analysis. Nat. Protoc. 8:1494-1512.

Hulbert, S. H. 1997. Structure and evolution of the rpl complex conferring rust resistance in maize. Annu. Rev. Phytopathol. 35:293-310.

Hulbert, S. H., Webb, C. A., Smith, S. M., and Sun, Q. 2001. Resistance gene complexes: Evolution and utilization. Annu. Rev. Phytopathol. 39:285-312.

Hundie, B., Girma, B., Tadesse, Z., Edae, E., Olivera, P., Abera, E. H., Bulbula, W. D., Abeyo, B., Badebo, A., Cisar, G., Brown-Guedira, G., Gale, S., Jin, Y., and Rouse, M. N. 2019. Characterization of Ethiopian wheat germplasm for resistance to four Puccinia graminis f. sp. tritici races facilitated by single-race nurseries. Plant Dis. 103:2359-2366.

Ishida, Y., Tsunashima, M., Hiei, Y., and Komari, T. 2015. Wheat (Triticum aestivum L.) transformation using immature embryos. Pages 189-198 in: Agrobacterium Protocols. K. Wang, ed. Methods in Molecular Biology, vol. 1223. Springer, New York, NY, U.S.A.

Jupe, F., Pritchard, L., Etherington, G. J., Mackenzie, K., Cock, P. J., Wright, F., Sharma, S. K., Bolser, D., Bryan, G. J., Jones, J. D., and Hein, I. 2012. Identification and localisation of the NB-LRR gene family within the potato genome. BMC Genomics 13:75.

Krasileva, K. V., Dahlbeck, D., and Staskawicz, B. J. 2010. Activation of an Arabidopsis resistance protein is specified by the in planta association of its leucine-rich repeat domain with the cognate oomycete effector. Plant Cell 22:2444-2458.

Kuang, H., Woo, S. S., Meyers, B. C., Nevo, E., and Michelmore, R. W. 2004. Multiple genetic processes result in heterogeneous rates of evolution within the major cluster disease resistance genes in lettuce. Plant Cell 16:2870-2894.

Mago, R., Zhang, P., Vautrin, S., Šimková, H., Bansal, U., Luo, M. C., Rouse, M., Karaoglu, H., Periyannan, S., Kolmer, J., Jin, Y., Ayliffe, M. A., Bariana, H., Park, R. F., McIntosh, R., Doležel, J., Bergès, H., Spielmeyer, W., Lagudah, E. S., Ellis, J. G., and Dodds, P. N. 2015. The wheat Sr50 gene reveals rich diversity at a cereal disease resistance locus. Nat. Plants 1: 15186.

Marcussen, T., Sandve, S. R., Heier, L., Spannagl, M., Pfeifer, M., Jakobsen, K. S., Wulff, B. B., Steuernagel, B., Mayer, K. F., and Olsen, O. A.; International Wheat Genome Sequencing Consortium. 2014. Ancient hybridizations among the ancestral genomes of bread wheat. Science 345:1250092. 
McIntosh, R., Dubcovsky, J., Rogers, W., Morris, C., and Xia, X. 2017. Catalogue of Gene Symbols for Wheat: 2017 Supplement. Komugi Wheat Genetic Resources Database, National BioResource Project. Kyoto, Japan.

Meyers, B. C., Chin, D. B., Shen, K. A., Sivaramakrishnan, S., Lavelle, D. O., Zhang, Z., and Michelmore, R. W. 1998a. The major resistance gene cluster in lettuce is highly duplicated and spans several megabases. Plant Cell 10:1817-1832.

Meyers, B. C., Dickerman, A. W., Michelmore, R. W., Sivaramakrishnan, S., Sobral, B. W., and Young, N. D. 1999. Plant disease resistance genes encode members of an ancient and diverse protein family within the nucleotide-binding superfamily. Plant J. 20:317-332.

Meyers, B. C., Kozik, A., Griego, A., Kuang, H., and Michelmore, R. W. 2003. Genome-wide analysis of NBS-LRR-encoding genes in Arabidopsis. Plant Cell 15:809-834.

Meyers, B. C., Shen, K. A., Rohani, P., Gaut, B. S., and Michelmore, R. W. 1998b. Receptor-like genes in the major resistance locus of lettuce are subject to divergent selection. Plant Cell 10:1833-1846.

Michelmore, R. W., and Meyers, B. C. 1998. Clusters of resistance genes in plants evolve by divergent selection and a birth-and-death process. Genome Res. 8:1113-1130.

Nazari, K., Mafi, M., Yahyaoui, A., Singh, R. P., and Park, R. F. 2009. Detection of wheat stem rust (Puccinia graminis f. sp. tritici) race TTKSK (Ug99) in Iran. Plant Dis. 93:317.

Nguyen, L. T., Schmidt, H. A., von Haeseler, A., and Minh, B. Q. 2015. IQTREE: A fast and effective stochastic algorithm for estimating maximum-likelihood phylogenies. Mol. Biol. Evol. 32:268-274.

Noël, L., Moores, T. L., van Der Biezen, E. A., Parniske, M., Daniels, M. J., Parker, J. E., and Jones, J. D. 1999. Pronounced intraspecific haplotype divergence at the RPP5 complex disease resistance locus of Arabidopsis. Plant Cell 11:2099-2111.

Olivera, P., Newcomb, M., Szabo, L. J., Rouse, M., Johnson, J., Gale, S., Luster, D. G., Hodson, D., Cox, J. A., Burgin, L., Hort, M., Gilligan, C. A., Patpour, M., Justesen, A. F., Hovmøller, M. S., Woldeab, G., Hailu, E., Hundie, B., Tadesse, K., Pumphrey, M., Singh, R. P., and Jin, Y. 2015. Phenotypic and genotypic characterization of race TKTTF of Puccinia graminis f. sp. tritici that caused a wheat stem rust epidemic in southern Ethiopia in 2013-14. Phytopathology 105:917-928.

Olivera Firpo, P. D., Newcomb, M., Flath, K., Sommerfeldt-Impe, N., Szabo, L. J., Carter, M., Luster, D. G., and Jin, Y. 2017. Characterization of Puccinia graminis f. sp. tritici isolates derived from an unusual wheat stem rust outbreak in Germany in 2013. Plant Pathol. 66:1258-1266.

Ori, N., Eshed, Y., Paran, I., Presting, G., Aviv, D., Tanksley, S., Zamir, D., and Fluhr, R. 1997. The $I 2 C$ family from the wilt disease resistance locus I2 belongs to the nucleotide binding, leucine-rich repeat superfamily of plant resistance genes. Plant Cell 9:521-532.

Park, R. 2016. Cereal rust report 2016, vol. 14. Plant Breeding Institute, Faculty of Agriculture and Environment, University of Sydney, Sydney, NSW, Australia.

Parniske, M., Hammond-Kosack, K. E., Golstein, C., Thomas, C. M., Jones, D. A., Harrison, K., Wulff, B. B., and Jones, J. D. 1997. Novel disease resistance specificities result from sequence exchange between tandemly repeated genes at the $C f-4 / 9$ locus of tomato. Cell 91:821-832.

Parniske, M., and Jones, J. D. 1999. Recombination between diverged clusters of the tomato $C f-9$ plant disease resistance gene family. Proc. Natl. Acad. Sci. U.S.A. 96:5850-5855.

Patpour, M., Hovmøller, M. S., Shahin, A. A., Newcomb, M., Olivera, P., Jin, Y., Luster, D., Hodson, D., Nazari, K., and Azab, M. 2016. First report of the Ug99 race group of wheat stem rust, Puccinia graminis $\mathrm{f}$. sp. tritici, in Egypt in 2014. Plant Dis. 100:863.

Periyannan, S., Moore, J., Ayliffe, M., Bansal, U., Wang, X., Huang, L., Deal, K., Luo, M., Kong, X., Bariana, H., Mago, R., McIntosh, R., Dodds, P., Dvorak, J., and Lagudah, E. 2013. The gene Sr33, an ortholog of barley Mla genes, encodes resistance to wheat stem rust race Ug99. Science 341:786-788.

Peterson, P. D. 2001. Stem Rust of Wheat: From Ancient Enemy to Modern Foe. American Phytopathological Society, St. Paul, MN, U.S.A.

Pretorius, Z. A., Bender, C. M., Visser, B., and Terefe, T. 2010. First report of a Puccinia graminis f. sp. tritici race virulent to the Sr24 and Sr31 wheat stem rust resistance genes in South Africa. Plant Dis. 94:784.

Pretorius, Z. A., Singh, R. P., Wagoire, W. W., and Payne, T. S. 2000. Detection of virulence to wheat stem rust resistance gene $S r 31$ in Puccinia graminis. f. sp. tritici in Uganda. Plant Dis. 84:203.

Pretorius, Z. A., Szabo, L. J., Boshoff, W. H. P., Herselman, L., and Visser, B. 2012. First report of a new TTKSF race of wheat stem rust (Puccinia graminis f. sp. tritici) in South Africa and Zimbabwe. Plant Dis. 96:590.

Price, M. N., Dehal, P. S., and Arkin, A. P. 2010. FastTree 2-Approximately maximum-likelihood trees for large alignments. PLoS One 5:e9490.
Rouse, M. N., and Jin, Y. 2011a. Genetics of resistance to race TTKSK of Puccinia graminis f. sp. tritici in Triticum monococcum. Phytopathology 101:1418-1423.

Rouse, M. N., and Jin, Y. 2011b. Stem rust resistance in A-genome diploid relatives of wheat. Plant Dis. 95:941-944.

Saintenac, C., Zhang, W., Salcedo, A., Rouse, M. N., Trick, H. N., Akhunov, E., and Dubcovsky, J. 2013. Identification of wheat gene Sr35 that confers resistance to Ug99 stem rust race group. Science 341:783-786.

Salcedo, A., Rutter, W., Wang, S., Akhunova, A., Bolus, S., Chao, S., Anderson, N., De Soto, M. F., Rouse, M., Szabo, L., Bowden, R. L., Dubcovsky, J., and Akhunov, E. 2017. Variation in the AvrSr35 gene determines $\mathrm{Sr} 35$ resistance against wheat stem rust race Ug99. Science 358:1604-1606.

Sánchez-Martín, J., Steuernagel, B., Ghosh, S., Herren, G., Hurni, S., Adamski, N., Vrána, J., Kubaláková, M., Krattinger, S. G., Wicker, T., Doležel, J., Keller, B., and Wulff, B. B. H. 2016. Rapid gene isolation in barley and wheat by mutant chromosome sequencing. Genome Biol. 17:221.

Serra, H., Choi, K., Zhao, X., Blackwell, A. R., Kim, J., and Henderson, I. R. 2018. Interhomolog polymorphism shapes meiotic crossover within the Arabidopsis RAC1 and RPP13 disease resistance genes. PLoS Genet. 14: e1007843.

Shamanin, V., Salina, E., Wanyera, R., Zelenskiy, Y., Olivera, P., and Morgounov, A. 2016. Genetic diversity of spring wheat from Kazakhstan and Russia for resistance to stem rust Ug99. Euphytica 212:287-296

Sievers, F., Wilm, A., Dineen, D., Gibson, T. J., Karplus, K., Li, W., Lopez, R., McWilliam, H., Remmert, M., Söding, J., Thompson, J. D., and Higgins, D. G. 2011. Fast, scalable generation of high-quality protein multiple sequence alignments using Clustal Omega. Mol. Syst. Biol. 7:539.

Singh, R. P., Hodson, D. P., Jin, Y., Huerta-Espino, J., Kinyua, M. G., Wanyera, R., Njau, P., and Ward, R. W. 2006. Current status, likely migration and strategies to mitigate the threat to wheat production from race Ug99 (TTKS) of stem rust pathogen. CAB Rev. 1:054.

Singh, R. P., Hodson, D. P., Jin, Y., Lagudah, E. S., Ayliffe, M. A., Bhavani, S., Rouse, M. N., Pretorius, Z. A., Szabo, L. J., Huerta-Espino, J., Basnet, B. R., Lan, C., and Hovmøller, M. S. 2015. Emergence and spread of new races of wheat stem rust fungus: Continued threat to food security and prospects of genetic control. Phytopathology 105: $872-884$.

Soreng, R. J., Peterson, P. M., Romaschenko, K., Davidse, G., Teisher, J. K., Clark, L. G., Barberá, P., Gillespie, L. J., and Zuloaga, F. O. 2017. A worldwide phylogenetic classification of the Poaceae (Gramineae) II: An update and a comparison of two 2015 classifications. J. Syst. Evol. 55:259-290.

Stahl, E. A., Dwyer, G., Mauricio, R., Kreitman, M., and Bergelson, J. 1999. Dynamics of disease resistance polymorphism at the Rpml locus of Arabidopsis. Nature 400:667-671.

Steuernagel, B., Periyannan, S. K., Hernández-Pinzón, I., Witek, K., Rouse, M. N., Yu, G., Hatta, A., Ayliffe, M., Bariana, H., Jones, J. D., Lagudah, E. S., and Wulff, B. B. 2016. Rapid cloning of disease-resistance genes in plants using mutagenesis and sequence capture. Nat. Biotechnol. 34: 652-655.

Steuernagel, B., Witek, K., Krattinger, S. G., Ramirez-Gonzalez, R. H., Schoonbeek, H.-j., Yu, G., Baggs, E., Witek, A. I., Yadav, I., Krasileva, K. V., Jones, J. D. G., Uauy, C., Keller, B., Ridout, C. J., and Wulff, B. B. H. 2018. Physical and transcriptional organisation of the bread wheat intracellular immune receptor repertoire. bioRxiv 339424.

Stöver, B. C., and Müller, K. F. 2010. TreeGraph 2: Combining and visualizing evidence from different phylogenetic analyses. BMC Bioinformatics 11:7.

Sun, Q., Collins, N. C., Ayliffe, M., Smith, S. M., Drake, J., Pryor, T., and Hulbert, S. H. 2001. Recombination between paralogues at the Rp1 rust resistance locus in maize. Genetics 158:423-438.

Terefe, T., Pretorius, Z. A., Visser, B. and Boshoff, W. H. P. 2018. First report of Puccinia graminis $\mathrm{f}$. sp. tritici race PTKSK, a variant of wheat stem rust race Ug99, in South Africa. Plant Dis. 103:1421.

The Angiosperm Phylogeny Group, Chase, M. W., Christenhusz, M. J. M., Fay, M. F., Byng, J. W., Judd, W. S., Soltis, D. E., Mabberley, D. J., Sennikov, A. N., Soltis, P. S., and Stevens, P. F. 2016. An update of the Angiosperm Phylogeny Group classification for the orders and families of flowering plants: APG IV. Bot. J. Linn. Soc. 181:1-20.

Thind, A. K., Wicker, T., Šimková, H., Fossati, D., Moullet, O., Brabant, C., Vrána, J., Doležel, J., and Krattinger, S. G. 2017. Rapid cloning of genes in hexaploid wheat using cultivar-specific long-range chromosome assembly. Nat. Biotechnol. 35:793-796.

Wang, M., Li, Z., Matthews, P. R., Upadhyaya, N. M., and Waterhouse, P. M. 1998. Improved vectors for Agrobacterium tumefaciens-mediated transformation of monocot plants. Acta Hortic. 461:401-408. 
Waterhouse, A. M., Procter, J. B., Martin, D. M., Clamp, M., and Barton, G. J. 2009. Jalview Version 2-A multiple sequence alignment editor and analysis workbench. Bioinformatics 25:1189-1191.

Weber, E., Engler, C., Gruetzner, R., Werner, S., and Marillonnet, S. 2011. A modular cloning system for standardized assembly of multigene constructs. PLoS One 6:e16765.

Wei, F., Wing, R. A., and Wise, R. P. 2002. Genome dynamics and evolution of the Mla (powdery mildew) resistance locus in barley. Plant Cell 14:1903-1917.
Zhang, J., Zhang, P., Dodds, P., and Lagudah, E. 2020. How targetsequence enrichment and sequencing (TEnSeq) pipelines have catalyzed resistance gene cloning in the wheat-rust pathosystem. Front. Plant Sci. 11:678.

Zhang, W., Chen, S., Abate, Z., Nirmala, J., Rouse, M. N., and Dubcovsky, J. 2017. Identification and characterization of $\mathrm{Sr} 13$, a tetraploid wheat gene that confers resistance to the $\mathrm{Ug} 99$ stem rust race group. Proc. Natl. Acad. Sci. U.S.A. 114:E9483-E9492. 